\title{
Paired evaluation of calvarial reconstruction with prototyped titanium implants with and without ceramic coating ${ }^{1}$
}

\author{
Davi Reis Calderoni', Rovilson Gilioli' ${ }^{I I}$, André Luiz Jardini Munhoz ${ }^{\mathrm{III}}$, Rubens Maciel Filho ${ }^{\mathrm{IV}}$, Cecília Amélia de Carvalho \\ Zavagliav $^{\mathrm{V}}$, Carlos Salles Lambert ${ }^{\mathrm{VI}}$, Éder Socrates Najar Lopes ${ }^{\mathrm{VII}}$, Ivan Felizardo Contrera Toro ${ }^{\mathrm{VIII}}$, Paulo Kharmandayan ${ }^{\mathrm{IX}}$ \\ IFellow PhD degree, Postgraduate Program in Surgical Sciences, Faculty of Medical Sciences, University of Campinas (UNICAMP), Brazil. Intellectual \\ and scientific content of the study, design the protocol, surgical procedures, acquisition and interpretation of data, statistical analysis, manuscript \\ writing. \\ IIPhD, Molecular Biology and Genetics. Head, Multidisciplinary Center for Biological Investigation on Laboratory Animals Science, UNICAMP, \\ Campinas-SP, Brazil. Surgical procedures, acquisition of data. \\ IIIPhD, Department of Products and Processes Development, School of Chemical Engineering, UNICAMP, Campinas-SP, Brazil. CNPq, Technical \\ Development and Innovation Productivity Grant Level 2. Intellectual and scientific content of the study, acquisition and interpretation of data. \\ ${ }^{I V}$ Full Professor, Department of Products and Processes Development, School of Chemical Engineering, UNICAMP, Campinas-SP, Brazil. CNPq, \\ Research Productivity Grant Level 1A. Intellectual and scientific content of the study. \\ ${ }^{\vee}$ Full Professor, Department of Materials Engineering, School of Mechanical Engineering, UNICAMP, Campinas-SP, Brazil. CNPq, Research \\ Productivity Grant Level 1A. Intellectual and scientific content of the study. \\ ${ }^{\mathrm{V}} \mathrm{PhD}$, Department of Applied Physics, Institute of Physics "Gleb Wataghin", UNICAMP, Campinas-SP, Brazil. Intellectual and scientific content of \\ the study, acquisition and interpretation of data. \\ ${ }^{\mathrm{VII}} \mathrm{PhD}$, Postgraduate Program in Mechanical Engineering, Department of Materials Engineering, School of Mechanical Engineering, UNICAMP, \\ Campinas-SP, Brazil. Acquisition and interpretation of data. \\ ${ }^{\mathrm{VIII}}$ Associate Professor, Division of Thoracic Surgery, Department of Surgery, Faculty of Medical Sciences, UNICAMP, Campinas-SP, Brazil. \\ Intellectual and scientific content of the study, critical revision. \\ ${ }^{\mathrm{IX}}$ Associate Professor, Head, Division of Plastic Surgery, Faculty of Medical Sciences, UNICAMP, Campinas-SP, Brazil. Intellectual and scientific \\ content of the study, design the protocol, surgical procedures, interpretation of data, manuscript writing, critical revision.
}

\begin{abstract}
PURPOSE: To investigate the osseointegration properties of prototyped implants with tridimensionally interconnected pores made of the $\mathrm{Ti}_{6} \mathrm{Al}_{4} \mathrm{~V}$ alloy and the influence of a thin calcium phosphate coating.

METHODS: Bilateral critical size calvarial defects were created in thirty Wistar rats and filled with coated and uncoated implants in a randomized fashion. The animals were kept for 15, 45 and 90 days. Implant mechanical integration was evaluated with a push-out test. Bone-implant interface was analyzed using scanning electron microscopy.

RESULTS: The maximum force to produce initial displacement of the implants increased during the study period, reaching values around $100 \mathrm{~N}$ for both types of implants. Intimate contact between bone and implant was present, with progressive bone growth into the pores. No significant differences were seen between coated and uncoated implants.
\end{abstract}

CONCLUSION: Adequate osseointegration can be achieved in calvarial reconstructions using prototyped $\mathrm{Ti}_{6} \mathrm{Al}_{4} \mathrm{~V}$ Implants with the described characteristics of surface and porosity.

Key words: Titanium. Skull. Osseointegration. Prostheses and Implants. Biocompatible Materials. Ceramics. Rats. 


\section{Introduction}

Cranioplasty is one of the oldest performed surgical procedures. Archeological evidence suggests that ancient civilizations attempted to perform cranioplasties with materials such as gold, shells and gourds. Since then different materials have been employed, with variable success ${ }^{1}$. In present times, despite the development of better implantable materials, surgeons are still challenged by the need for safer and more precise reconstructions, especially in terms of recreating as normal a cranial tridimensional contour as possible.

Titanium and its alloys have been widely used in the field of surgery for the construction of implantable devices. Their biocompatibility has been extensively demonstrated, especially related to bone, both experimentally ${ }^{2-5}$ and clinically ${ }^{6-9}$ with variable implant designs and methods of construction.

In an attempt to improve bone contact and integration with the reconstruction material, ceramics have been employed either as single constituent of implants or mainly as coating materials. The ceramic coating of metallic implants functions as a transition layer between bone tissue and the non-physiological metal surface, enhancing the contact and conducting bone growth along the surface of the implant ${ }^{10}$. Calcium phosphate coatings are reported to increase contact between bone and implant ${ }^{11}$, and to enhance implant fixation, including a facilitation of bone growth over gaps between the two surfaces ${ }^{12}$.

Rapid prototyping methods have been employed for a long time in fields where precise building of complex structures was necessary, such as aerospace engineering and racing cars development $^{5}$. These properties were more recently found useful in medical sciences, especially regarding biomaterials research, giving rise to studies of complex geometry implant construction ${ }^{13}$. There is also some evidence of good osseointegration of titanium implants built by rapid prototyping in facial bone $\mathrm{e}^{14}$.

The goals of this study were to evaluate the osseointegration properties of porous prototyped implants with tridimensionally interconnected pores made of the $\mathrm{Ti}_{6} \mathrm{Al}_{4} \mathrm{~V}$ alloy in the setting of cranial reconstruction, and possible influences of a thin layer of calcium phosphate coating, using a model of critical size cranial defect in rats.

\section{Methods}

The study protocol was fully approved by the Committee for Ethics in Animal Research of the University of Campinas UNICAMP, under the number 2252-1, and complied with the
Council for International Organization of Medical Sciences (CIOMS) ethical code for animal experimentation.

\section{Implant design and construction}

Implants were designed in a round shape, with a diameter of $5 \mathrm{~mm}$. Two interconnected porous layers were built, with each pore having a diameter of $500 \mu \mathrm{m}$ (Figure 1). Construction was performed using titanium-aluminum-vanadium $\left(\mathrm{Ti}_{6} \mathrm{Al}_{4} \mathrm{~V}\right)$ alloy powder (EOS Titanium Ti64, EOS GmbH - Electro Optical Systems; Munich, Germany), which was processed by direct metal laser sintering (DMLS) using an EOSINT M 270 (EOS GmbH) equipment.

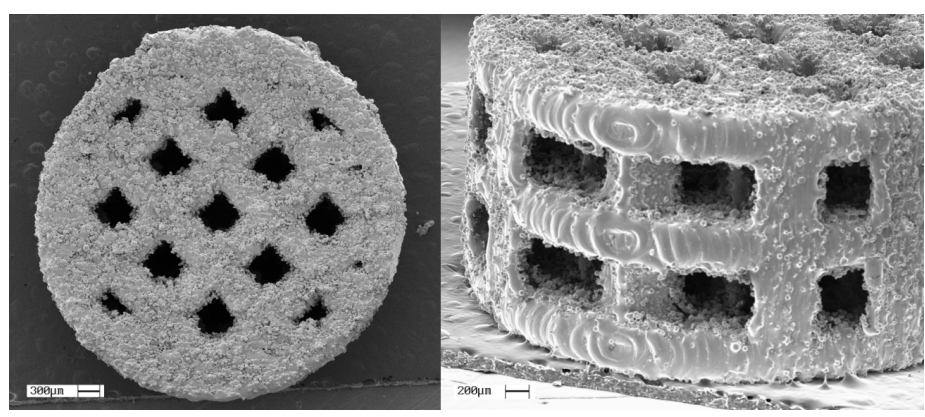

FIGURE 1 - SEM images of prototyped $\mathrm{Ti}_{6} \mathrm{Al}_{4} \mathrm{~V}$ scaffold, depicting the porosity and surface roughness obtained (Magnification: x40 left; x65 right).

\section{Ceramic coating}

Coating of the implants with $\beta$-tricalcium phosphate $(\beta$-TCP) was performed using radiofrequency assisted physical vapor deposition. The used parameters were $30 \mathrm{~W}$ source power and a pressure of $4 \times 10^{-2}$ Torr, with a duration of 25 minutes. This resulted in a coating thickness of $100 \mathrm{~nm}$.

\section{Surgical procedure}

Thirty male, three month-old, Wistar rats were operated. The procedure was performed under general anesthesia with intraperitonially administered xylazine (Xilazin ${ }^{\circledR}$, Syntec do Brasil Ltda., Cotia, Brazil) and ketamine $\left(\right.$ Cetamin $^{\circledR}$, Syntec do Brasil Ltda., Cotia, Brazil). The animals were immobilized using a stereotaxic surgery frame. A median incision was made in the scalp and periosteum, which was laterally dissected from the calvarium using an elevator. Two parallel, full-thickness craniotomies with $5 \mathrm{~mm}$ diameter was then performed on the parietal bones using a low-speed drill under saline irrigation, according to the critical size defect proposed by Bosch ${ }^{15}$. Each animal received one $\mathrm{Ti}_{6} \mathrm{Al}_{4} \mathrm{~V}$ and one $\mathrm{Ti}_{6} \mathrm{Al}_{4} \mathrm{~V}+\beta$-TCP implant. The position of the implants was randomized between left and right sides using a list of randomized 
positions for the $\mathrm{Ti}_{6} \mathrm{Al}_{4} \mathrm{~V}+\beta$ - TCP implant provided by an online random number generator (available at www.randomization.com). Then, periosteum and scalp were separately sutured using 5-0 nylon sutures. Each animal was numbered and separated into three groups that would be kept for different periods before euthanasia, i.e. 15,45 and 90 days.

\section{Animal sacrifice and material retrieval}

The animals were euthanized in groups after the assigned postoperative periods, using a carbon dioxide inhalation chamber.

The scalp over the operated region was removed and after careful macroscopic observation and periosteal dissection, the uppermost part of the cranium was cut off at the levels of temporal, occipital and frontal bones, including both implants fully surrounded by uninjured bone. Specimens were initially kept in saline solution and refrigerated to preserve fresh tissue characteristics.

\section{Push-out tests}

Push-out tests were performed using a mechanical essay equipment, model DL 2000 (EMIC Equipamentos e Sistemas de Ensaio LTDA, São José dos Pinhais, Brazil), with a $500 \mathrm{~N}$ probe model CCE500N (EMIC). Acquired data were processed with TESC version 3.04 software (EMIC).

The tests were performed in an up to 24-hour period following obtainment of the samples. The cranial bone containing the implants was carefully positioned over a centrally perforated stand, with the convex outer face down. The stand hole had a larger diameter than the one of the implant in order not to restrain its downward movement during the test. Each implant was tested separately after proper positioning over the stand. The test was conducted in a nondestructive fashion. The execution of each essay was followed in real time through a force $\mathrm{x}$ time graph exhibited by the software. Once the maximum force (Fmax) was reached and its values constantly decreased, the test was interrupted.

\section{Samples preparation and cutting}

After the push-out tests, samples were fixed in formaldehyde solution and embedded in resin. Cutting of the samples was performed using a Model 650 Low Speed Diamond Wheel Saw (South Bay Technologies, Inc., San Clemente, USA) and a four inch diamond waffering blade (Buehler, Lake Bluff, USA). The blocks were cut with a coronal plane orientation, initially tangential to the anterior edges of both implants. Two sequential $1 \mathrm{~mm}$-thick cuts were made starting from the anterior edge in a posterior direction, in order to analyze the interior of the implants.

\section{Scanning electron microscopy analyses}

Microscopic analyses were always performed on the occipital face of the cuts. Samples were coated with gold using a Sputter Coater Model SC7620 (Quorum Technologies Ltd., Ashford, United Kingdom). Scanning electron microscopy (SEM) images and energy-dispersive X-ray spectroscopy (EDS) were obtained with a Leo 440i microscope coupled with a EDS detector model 6070 (LEO Electron Microscopy, Cambridge, United Kingdom).

EDS dot mapping images were obtained using the following parameters: magnification of 50x, beam acceleration of $20 \mathrm{kV}$ and acquisition time of three minutes. The chosen elements for image construction were Titanium (red dots) and Calcium (green dots).

All SEM and EDS images analyzed correspond to the occipital (posterior) surface of the second $1 \mathrm{~mm}$ cut, i.e. $2 \mathrm{~mm}$ from the frontal (anterior) edge of the implants.

\section{Statistical analysis}

Statistical analysis was performed using Bioestat 5.0 software (Instituto de Desenvolvimento Sustentável Mamirauá, Tefé, Brazil). The continuous variable "Force" obtained from pushout tests was analyzed for normal distribution within groups using the Shapiro-Wilk test. Intragroup comparisons between the different types of implants were done by using two-tailed Student's t-test for paired samples. Comparisons between different time groups were performed by using single-factor Analysis of Variance (ANOVA) test.

\section{Results}

All animals had an uneventful postoperative course and exhibited normal behavior and no discernible deficits, except for one pertaining to the third operated group (15 days), which died minutes after the surgical procedure, probably due to anesthetic prolonged effect.

\section{Macroscopic evaluation}

Wound healing was considered satisfactory and no noticeable scalp scars were seen at the time of necropsies. After scalp removal, complete periosteal healing was observed in all animals, with no gross signs of inflammation. Also, during periosteal elevation from the calvarium, a firm adhesion of the former to the upper surface of the implant was invariably present (Figure 2- Left). 
Once the bone specimens were retrieved, it was observed that the implants were surrounded by bone of normal appearance, with no signs of interposed fibrous tissue. On the inner surface of the specimens, bone ingrowth towards the implant pores could be seen, especially in those pertaining to the animals of 45-day and 90-day groups (Figure 2 - Right). By applying gentle pressure over the implants no visible movement ensued.

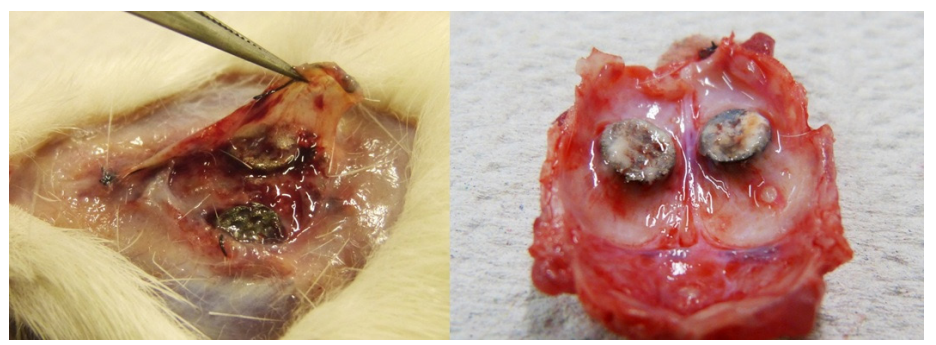

FIGURE 2 - Dissection performed after animal sacrifice showing firm periosteal adhesion to the surface of the implant (left). Inner surface of the specimen recovered exhibiting growth of bone into the pores of the implant (right).

\section{Push-out tests}

The mean Fmax required to disrupt the implant-bone interface was progressively higher from the 15-day to the 90-day groups and this tendency was observed for both types of implants. Comparison of the values among the groups revealed that forces needed to displace either type of implant after 45 and 90 days were significantly higher than those needed at 15 days. Differences between values for each type of implant at 45 and 90 days groups did not reach statistical significance. No significant differences were observed between the mean maximum forces within groups between $\mathrm{Ti}_{6} \mathrm{Al}_{4} \mathrm{~V}$ and $\mathrm{Ti}_{6} \mathrm{Al}_{4} \mathrm{~V}+\beta$ - $\mathrm{TCP}$ implants (Table 1).

TABLE 1 - Mean results of push-out tests for type of implant and groups (Fmax values in Newtons).

\begin{tabular}{cccc}
\hline & $\mathbf{1 5}$ days & 45 days & 90 days \\
\hline $\mathbf{T i}_{\mathbf{6}} \mathbf{A l} \mathbf{l}_{\mathbf{V}} \mathbf{V}$ & 21.3 & $98.7^{*}$ & $97.3^{*}$ \\
$\mathbf{T i}_{\mathbf{6}} \mathbf{A l}_{\mathbf{4}} \mathbf{V}+\beta-\mathbf{T C P}$ & 12.4 & $83.6^{\#}$ & $93.4^{\#}$ \\
\hline
\end{tabular}

${ }^{*} \mathrm{p}<0.05$ compared to mean value for $\mathrm{Ti}_{6} \mathrm{Al}_{4} \mathrm{~V}$ at 15 days.

" $\mathrm{p}<0.05$ compared to mean value for $\mathrm{Ti}_{6} \mathrm{Al}_{4} \mathrm{~V}+\beta-\mathrm{TCP}$ at 15 days.

\section{SEM and EDS analyses}

Standard SEM images better evaluated growth of bone into the pores, especially the more centrally located ones as seen on the coronal cuts of the implants. A progressive filling of the pores by bone was observed between the groups, with the 90-day one exhibiting the highest occupation. This tendency was equally present in both types of implants (Figures 3 and 4). Also, intimate contact between newly formed bone and the inner surface of the channels could be observed and confirmed by EDS spectra (Figure 5).

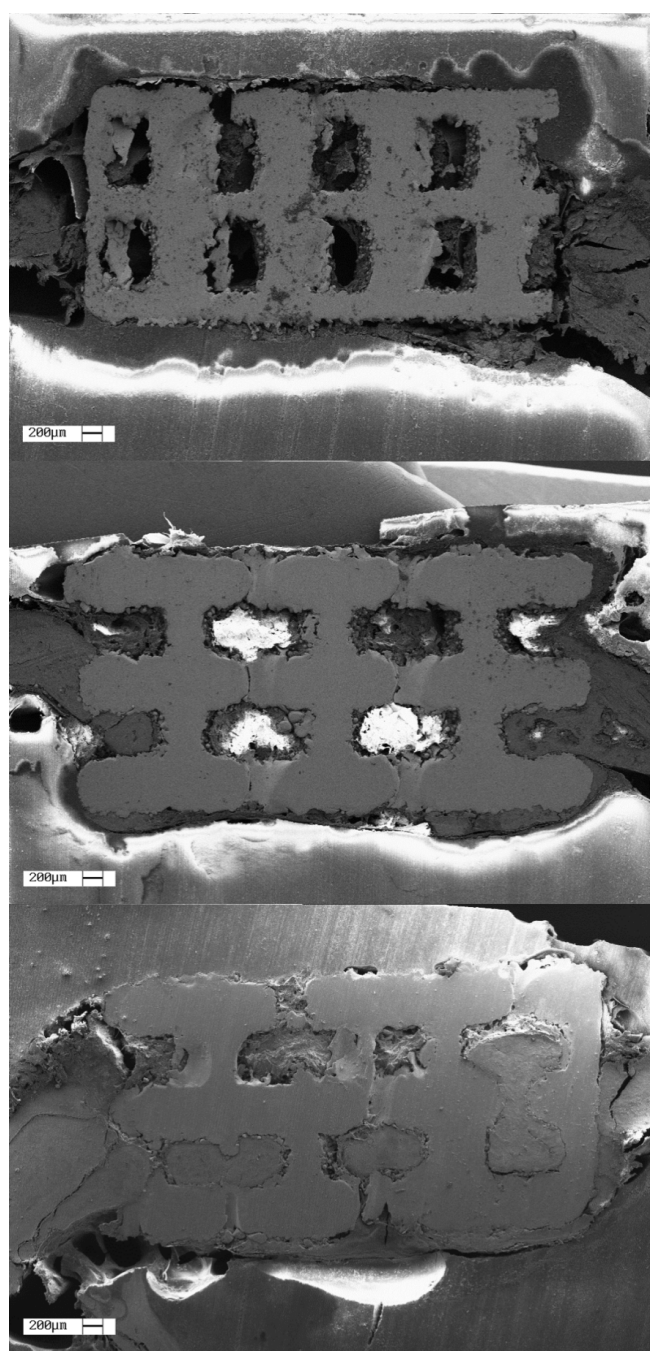

FIGURE 3 - SEM images of $\mathrm{Ti}_{6} \mathrm{Al}_{4} \mathrm{~V}$ implants at 15-day (upper), 45day (center) and 90-day (lower) stages, showing progressive increase in pores occupation by bone ingrowth (Magnification x50). 

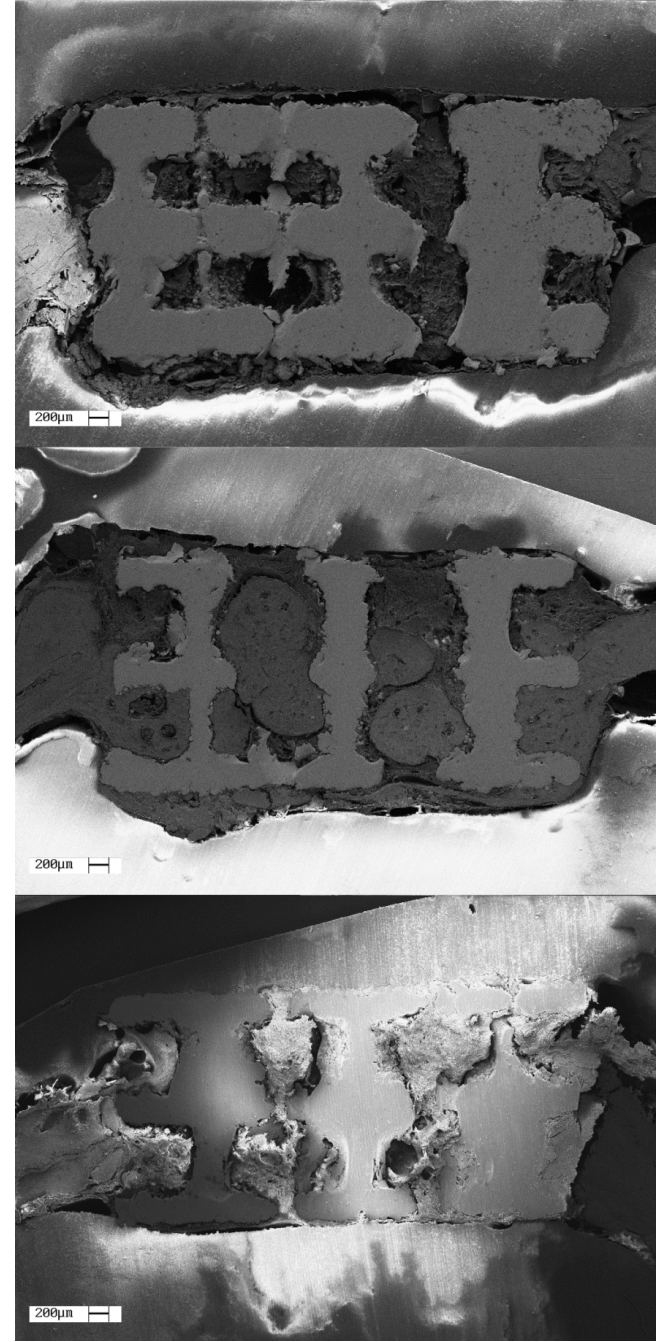

FIGURE 4 - SEM images of $\mathrm{Ti}_{6} \mathrm{Al}_{4} \mathrm{~V}+\beta$-TCP implants at 15 -day (upper), 45-day (center) and 90-day (lower) stages, showing progressive increase in pores occupation by bone ingrowth (Magnification x50).

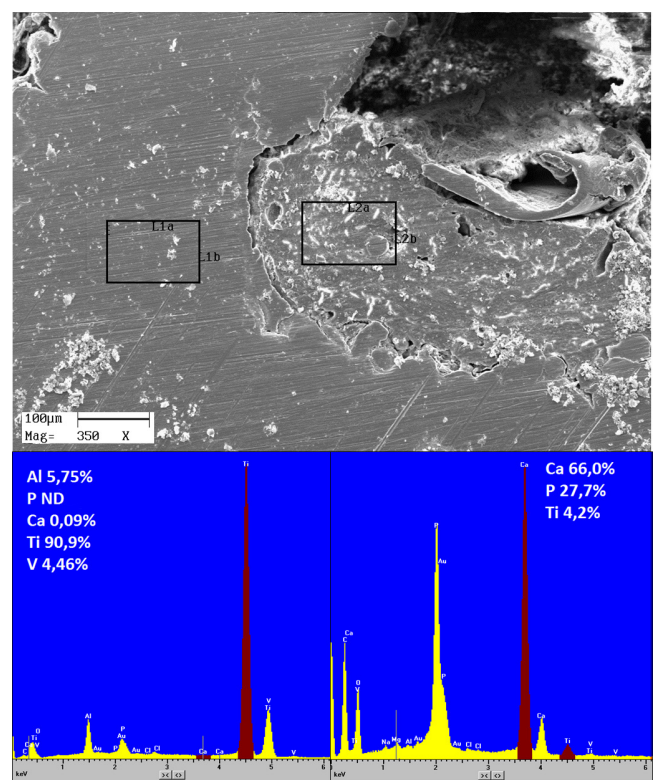

FIGURE 5 - Close-up of the internal wall of a pore of a $\mathrm{Ti}_{6} \mathrm{Al}_{4} \mathrm{~V}$ implant belonging to the 90-day group. EDS spectra demonstrating the presence of bone (Region L2 - right spectrum) in intimate contact with the scaffold surface (Region L1 - left spectrum) (Magnification x350).
Dot map images obtained using EDS technique were useful to assess the morphology of the cranial bone surrounding the implants as well as the bone/implant interface. By comparing images obtained from the three groups, some enlargement of the native bone's edge in contact with the implant as well as progressive bone penetration into the peripheral pores was noticed. Animals from the 15-day group exhibited thinner bone edges surrounding the implant and poorer contact was seen between them. Both 45 and 90-day groups' cuts showed similar appearances, in which native bone edges had greater contact with the lateral implant surface. Also, bone growth was seen towards both levels of pores and on the lower surface (which was in contact with the dura mater) of some implants (Figures 6 and 7).

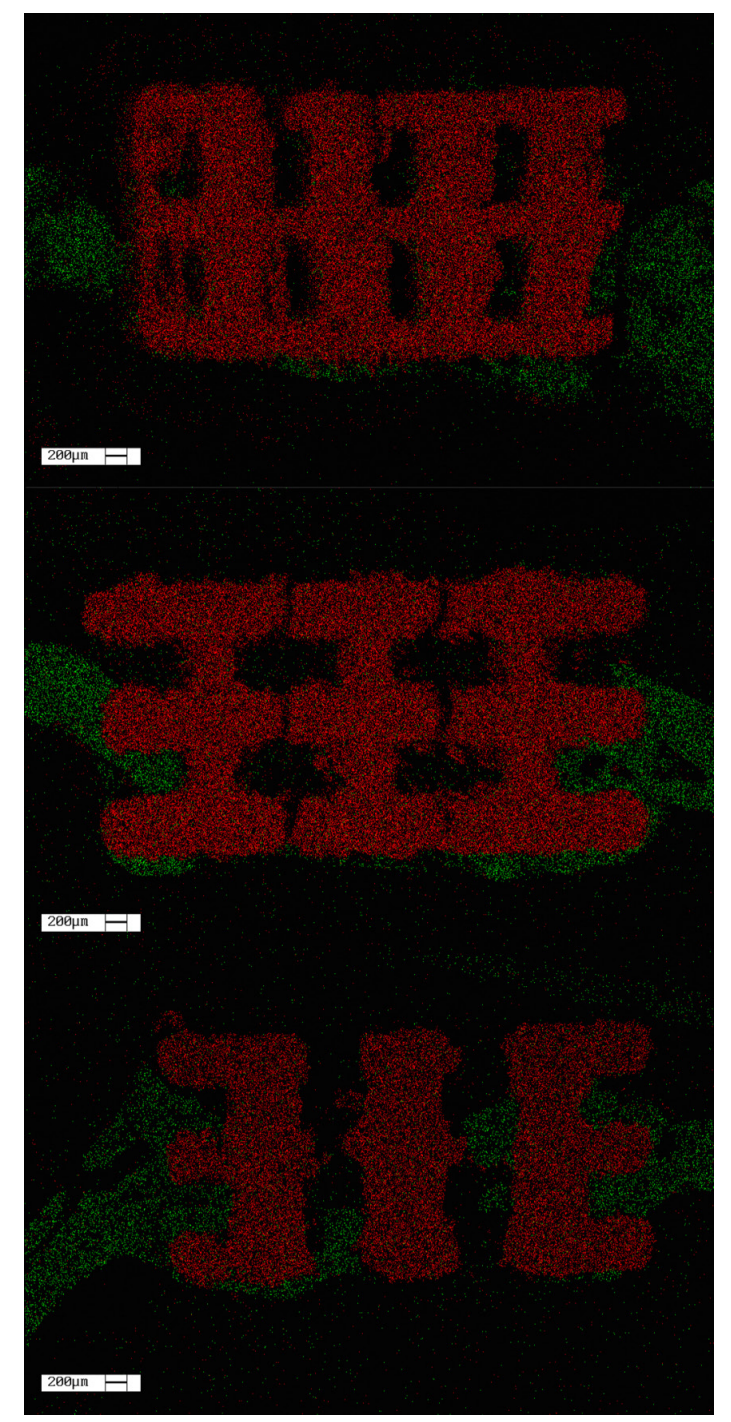

FIGURE 6 - EDS dot map images of $\mathrm{Ti}_{6} \mathrm{Al}_{4} \mathrm{~V}$ implants at 15-day (upper), 45-day (center) and 90-day (lower) stages, showing progressive enhancement of bone contact with the lateral surface of the implants and growth of bone into the pores (Red dots: Titanium; Green dots: Calcium. Magnification x50). 


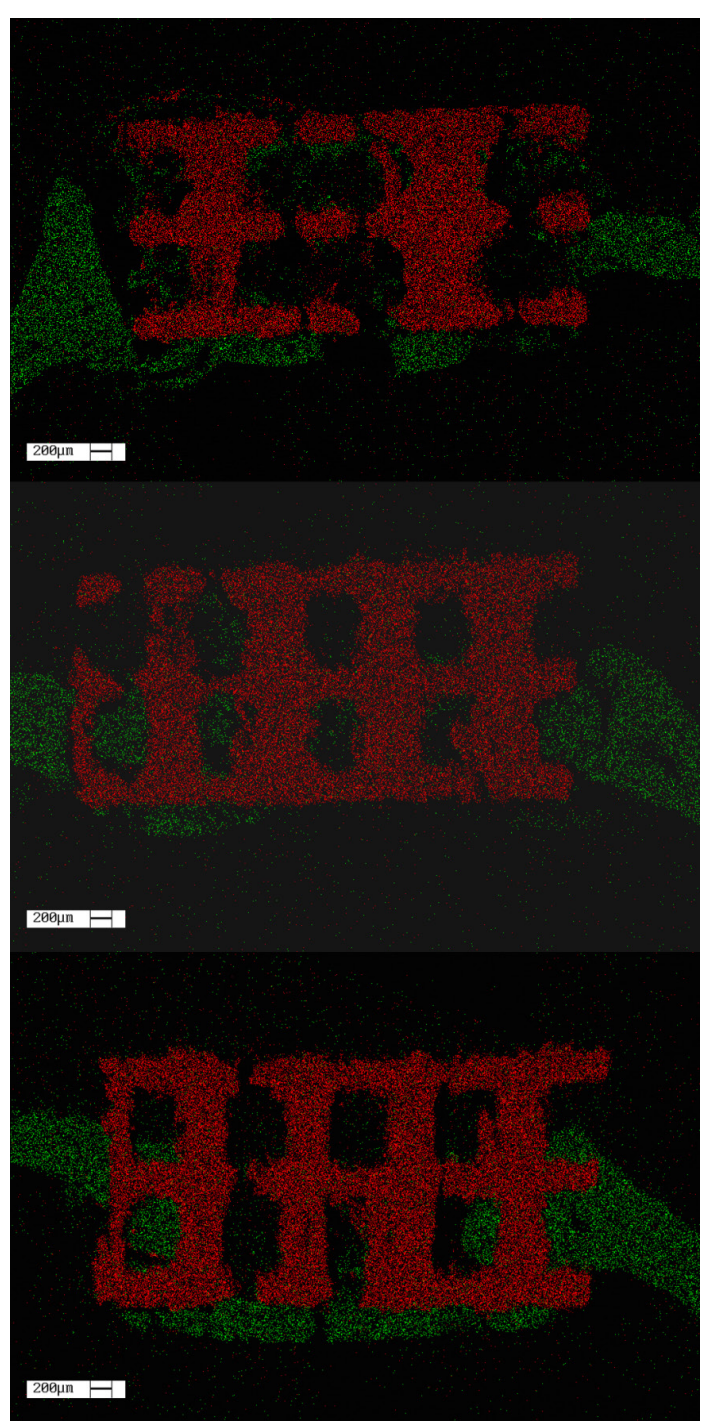

FIGURE 7 - EDS dot map images of $\mathrm{Ti}_{6} \mathrm{Al}_{4} \mathrm{~V}+\beta$-TCP implants at 15 -day (upper), 45-day (center) and 90-day (lower) stages, showing progressive enhancement of bone contact with the lateral surface of the implants and growth of bone into the pores (Red dots: Titanium; Green dots: Calcium. Magnification x50).

\section{Discussion}

Titanium and its alloys are extensively used to produce implants for bone reconstruction and fixation due to their biocompatibility ${ }^{10,16}$. Recently, the incorporation of rapid prototyping methods allowed the construction of more precise and customized implants, a great advantage in the setting of craniofacial reconstruction ${ }^{17}$. The aim of this study was to evaluate the osseointegration capability of customized $\mathrm{Ti}_{6} \mathrm{Al}_{4} \mathrm{~V}$ implants produced by DMLS, with and without a thin $\beta$-TCP coating, in a rat cranial reconstruction model.

The experimental animal model employed in this study of bilateral parietal $5 \mathrm{~mm}$ craniotomies has been frequently used due to its favorable characteristics, the main one being the ability to produce paired analysis. It also fulfills the criteria for a critical size defect, and allows for the evaluation of biomaterials for bone reconstruction ${ }^{15,18,19}$

In macroscopic observations an invariably firm periosteal adhesion was seen over all outer implant surfaces. Moreover, surrounding bone was closely in contact with the implants, without any discernible mobility or interposed fibrous tissue. Also, the fact that the implants were slightly thicker than the calvarial bone allowed a clear visualization of bone ingrowth towards the lateral pores (Figure 2). These observations were confirmed by SEM images, which showed progressive centripetal bone filling of both levels of pores, with close contact between bone and implant surface.

The described findings agree with the described characteristics of biocompatibility exhibited by titanium and its alloys with bone tissue. Several studies have demonstrated these properties either with osteoblast cultures ${ }^{5,20}$ or with in vivo experiments ${ }^{3,4,11}$.

Integration between bone and implants was further demonstrated by push-out test results. It is accepted that such tests are able to estimate the mechanical interlocking between bone and implant ${ }^{21}$. The results of push-out tests demonstrated that a considerably high force was required to disrupt the boneimplant interface, and that it was increasingly higher as the period elapsed between surgery and sacrifice grew, reaching values around $100 \mathrm{~N}$. These data indirectly demonstrate the progressive ingrowth of bone towards the implant that took place mainly during the period between 15 and 45 days, which was also demonstrated by the SEM and EDS images.

There are few studies in the literature that used pushout tests to evaluate the strength of the bone-implant interface in the calvaria, although this method is widely employed in other experimental bone surgery models, such as those of long bones of the $\operatorname{limbs}^{22,23}$. In an evaluation of the influence of growth hormone supplementation on calvarial healing using an identical experimental model, a Fmax of $14.1 \pm 5.1 \mathrm{~N}$ was exerted on the defect of the placebo group and $35.4 \pm 10.3 \mathrm{~N}$ in the treatment group until a fracture ensued ${ }^{24}$. Some papers evaluating a variety of biomaterials for calvarial reconstruction in rats by means of pushout tests executed similarly to what was done in our study had variable results. In the study of Jones et al. ${ }^{18}$ Fmax values around $50 \mathrm{~N}$ and $30 \mathrm{~N}$ were obtained after 3 months of reconstruction with demineralized bone matrix (DBM) and bone grafts respectively. Two studies assessing reconstruction with scaffolds treated with growth factors obtained a Fmax of $130 \mathrm{~N}$ for implants made of polycaprolactone and collagen treated with bone morphogenetic 
protein-2 (BMP-2) after 15 weeks $^{25}$, and of $138 \mathrm{~N}$ using calcium deficient hydroxyapatite (CDHA) implants coated with chitosan and treated with BMP-2 after eight weeks ${ }^{26}$.

No studies were found applying push-out tests to evaluate calvarial reconstructions with titanium implants and, to the best of our knowledge, this is the first one to do so. The obtained Fmax values demonstrate that there was progressive strengthening of the interface between bone and both types of scaffold during the studied period. Comparing these with the previous literature findings, it can be noticed that they were superior to what has been found with traditionally employed materials such as autologous bone grafts, which is considered by many as the standard material for calvarial reconstruction, as well as with DBM and purely ceramic implants (in the paper by Zhao et al. ${ }^{26}$, scaffolds made solely with CDHA obtained a Fmax of $72 \mathrm{~N}$ after eight weeks). Besides that, the Fmax values obtained with the titanium scaffolds in our study were close to the ones required for fracturing intact calvarial bones of 12-week-old rats, which were found to range from $80 \mathrm{~N}$ to $100 \mathrm{~N}^{25}$.

The variation of Fmax values among the experimental groups shows that most of bone ingrowth occurred until 45 days after the surgical procedure, with no significant improvement after this period (no statistically significant difference between 45-day and 90-day groups). This evolution pattern was also observed in other experimental in vivo studies ${ }^{18,27}$ and pointed out in a recent review on critical size calvarial defects in rats ${ }^{19}$.

It is generally reported in the literature that ceramic coatings improve the osseointegration of metallic scaffolds by promoting the filling of gaps between bone and implant ${ }^{12}$, enhancing bone contact with the implant surface s1,28 $^{11}$ and possessing osteoinductive properties ${ }^{29,30}$. However, the results of experimental studies comparing titanium implants with and without ceramic coatings have conflicting results, with evidence either of lack of benefit ${ }^{31-35}$ or superior results ${ }^{11,12,28,36}$ with bone growth acceleration ${ }^{37}$. Taking together the results of push-out tests and SEM images observations, it was not possible to demonstrate a benefit of the $\beta$-TCP coating. It is possible that the employed coating characteristics were not adequate to promote or enhance bone ingrowth to an extent that was significantly different from what was observed with the uncoated scaffolds.

The concept that drove the design of the scaffolds used in this study was to obtain osseointegrated customized titanium implants build by rapid prototyping. This would allow for better results in terms of contour and symmetry, which are of vital importance in craniofacial reconstruction and a drawback of traditional methods. Besides, complications such as postoperative implant displacement, infections and implant exposure could be potentially reduced ${ }^{6}$. On other advantage would be the reduction of operative time, since time consuming intraoperative modeling would not be necessary ${ }^{17}$.

Recent reviews emphasized the pivotal role of implant surface physical components (mainly porosity and roughness) to promote adequate ossointegration ${ }^{38-40}$. Additionally, there is a chemical component that can be added, mainly ceramic coatings, in an attempt to establish a more receptive surface for cell adhesion by mimicking bone tissue and enabling ionic exchanges with host tissue ${ }^{10}$.

It has been demonstrated that the scaffold design and building method used in our study were able to provide an optimal environment for bon ingrowth, since the key physical elements that favor osseointegration were present, i.e. tridimensionally interconnected pores with adequate diameter and a sufficiently irregular surface to promote cell adhesion and osteoconduction. The lack of benefit of the ceramic coating in our study could be attributed either to non-ideal settings of the produced coating, such as its thickness, or to an already satisfactory enough result of the uncoated implant that could hinder the detection of an eventual influence. It is possible then that in the setting of calvarial reconstruction the addition of a ceramic coating would not be essential, once an adequately designed implant is provided.

\section{Conclusion}

Adequate osseointegration can be achieved in calvarial reconstructions using prototyped $\mathrm{Ti}_{6} \mathrm{Al}_{4} \mathrm{~V}$ scaffolds with the described physical characteristics of surface and porosity.

\section{References}

1. Sanan A, Haines SJ. Repairing holes in the head: a history of cranioplasty. Neurosurgery. 1997 Mar;40(3):588-603. PMID: 9055300

2. Bandyopadhyay A, Espana F, Balla VK, Bose S, Ohgami Y, Davies NM. Influence of porosity on mechanical properties and in vivo response of Ti6Al4V implants. Acta Biomater. 2010 May;6(4):1640 8. doi: 10.1016/j.actbio.2009.11.011

3. Vehof JWM, Haus MTU, de Ruijter AE, Spauwen PHM, Jansen J a. Bone formation in transforming growth factor beta-I-loaded titanium fiber mesh implants. Clin Oral Implants Res. 2002 Mar;13(1):94 102. doi: 10.1034/j.1600-0501.2002.130112.x

4. Ponader S, von Wilmowsky C, Widenmayer M, Lutz R, Heinl P, Körner C, Singer RF, Nkenke E, Neukam FW, Schlegel KA. In vivo performance of selective electron beam-melted Ti-6Al-4V structures. J Biomed Mater Res A. 2010 Jan;92(1):56-62. doi: 10.1002/jbm.a.32337 
5. Warnke PH, Douglas T, Wollny P, Sherry E, Steiner M, Galonska S, Becker ST, Springer IN, Wiltfang J, Sivananthan S. Rapid prototyping: porous titanium alloy scaffolds produced by selective laser melting for bone tissue engineering. Tissue Eng Part C Methods. 2009 Jul;15(2):115-24. doi: 10.1089/ten.tec.2008.0288

6. Neovius E, Engstrand T. Craniofacial reconstruction with bone and biomaterials: review over the last 11 years. J Plast Reconstr Aesthet Surg. 2010 Oct;63(10):1615-23. doi: 10.1016/j.bjps.2009.06.003

7. Cabraja M, Klein M, Lehmann T-N. Long-term results following titanium cranioplasty of large skull defects. Neurosurg Focus. 2009 Jul;26(6):E10. doi: 10.3171/2009.3.FOCUS091

8. Kuttenberger JJ, Hardt N. Long-term results following reconstruction of craniofacial defects with titanium micro-mesh systems. J Craniomaxillofac Surg. 2001 Apr;29(2):75-81. doi:10.1054/ jems.2001.0197

9. Joffe J, Harris M, Kahugu F, Nicoll S. A prospective study of computer-aided design and manufacture of titanium plate for cranioplasty and its clinical outcome. Br J Neurosurg. 1999 Dec;13(6):576-80. PMID: 10715726

10. De Jonge LT, Leeuwenburgh SCG, Wolke JGC, Jansen JA. Organicinorganic surface modifications for titanium implant surfaces. Pharm Res. 2008 Oct;25(10):2357-69. doi: 10.1007/s11095-008-9617-0

11. Dhert WJ, Klein CP, Jansen JA, van der Velde EA, Vriesde RC, Rozing PM, de Groot K. A histological and histomorphometrical investigation of fluorapatite, magnesiumwhitlockite, and hydroxylapatite plasma-sprayed coatings in goats. J Biomed Mater Res. 1993 Jan;27(1):127-38. doi: 10.1002/jbm.820270116

12. Søballe K, Hansen ES, Brockstedt-Rasmussen H, Hjortdal VE, Juhl GI, Pedersen CM, Hvid I, Bünger C. Gap healing enhanced by hydroxyapatite coating in dogs. Clin Orthop Relat Res. 1991 Nov;(272):300-7. PMID: 1657476

13. Goiato MC, Santos MR, Pesqueira AA, Moreno A, dos Santos DM, Haddad MF. Prototyping for surgical and prosthetic treatment. J Craniofac Surg. 2011 May;22(3):914-7. doi: 10.1097/ SCS.0b013e31820f7f90

14. Mangano C, Piattelli A, Raspanti M, Mangano F, Cassoni A, Iezzi G, Shibli JA. Scanning electron microscopy (SEM) and X-ray dispersive spectrometry evaluation of direct laser metal sintering surface and human bone interface: a case series. Lasers Med Sci. 2011 Jan;26(1):133-8. doi: 10.1007/s10103-010-0831-8

15. Bosch C, Melsen B, Vargervik K. Importance of the critical-size bone defect in testing bone-regenerating materials. J Craniofac Surg. 1998 Jul;9(4):310-6. PMID: 9780924

16. Akagawa Y, Abe Y. Titanium: the ultimate solution or an evolutionary step? Int J Prosthodont. 2003 Jan;16 Suppl:28-9. PMID: 14661700

17. Chim H, Schantz J-T. New frontiers in calvarial reconstruction: integrating computer-assisted design and tissue engineering in cranioplasty. Plast Reconstr Surg. 2005 Nov;116(6):1726-41. doi: 10.1097/01.prs.0000182386.78775.cd

18. Jones L, Thomsen JS, Mosekilde L, Bosch C, Melsen B. Biomechanical evaluation of rat skull defects, 1,3 , and 6 months after implantation with osteopromotive substances. J Craniomaxillofac Surg. 2007 Dec;35(8):350-7. doi: 10.1016/j.jcms.2007.06.004

19. Vajgel A, Mardas N, Farias BC, Petrie A, Cimões R, Donos N. A systematic review on the critical size defect model. Clin Oral Implants Res. 2014 Aug;25(8):879-93. doi: 10.1111/clr.12194

20. Frosch K-H, Barvencik F, Lohmann CH, Viereck V, Siggelkow H, Breme J, Dresing K, Stürmer KM. Migration, matrix production and lamellar bone formation of human osteoblast-like cells in porous titanium implants. Cells Tissues Organs. 2002 Jan;170(4):214-27. doi: 10.1159/000047925

21. Dhert WJ, Verheyen CC, Braak LH, de Wijn JR, Klein CP, de Groot K, Rozing PM. A finite element analysis of the push-out test: influence of test conditions. J Biomed Mater Res. 1992 Jan;26(1):119-30. doi: $10.1002 / \mathrm{jbm} .820260111$

22. Babiker H, Ding M, Sandri M, Tampieri A, Overgaard S. The effects of bone marrow aspirate, bone graft, and collagen composites on fixation of titanium implants. J Biomed Mater Res B Appl Biomater. 2012 May;100(3):759-66. doi: 10.1002/jbm.b.32509

23. Chung C-J, Su R-T, Chu H-J, Chen H-T, Tsou H-K, He J-L. Plasma electrolytic oxidation of titanium and improvement in osseointegration. J Biomed Mater Res B Appl Biomater. 2013 Aug;101(6):1023-30. doi: 10.1002/jbm.b.32912

24. Cacciafesta V, Dalstra M, Bosch C, Melsen B, Andreassen TT. Growth hormone treatment promotes guided bone regeneration in rat calvarial defects. Eur J Orthod. 2001 Dec;23(6):733-40. doi: 10.1093/ejo/23.6.733

25. Sawyer AA, Song SJ, Susanto E, Chuan P, Lam CXF, Woodruff MA, Hutmacher DW, Cool SM. The stimulation of healing within a rat calvarial defect by $\mathrm{mPCL}-\mathrm{TCP} /$ collagen scaffolds loaded with rhBMP-2. Biomaterials. 2009 May;30(13):2479-88. doi: 10.1016/j. biomaterials.2008.12.055

26. Zhao J, Shen G, Liu C, Wang S, Zhang W, Zhang X, Zhang X, Ye D, Wei J, Zhang Z, Jiang X. Enhanced healing of rat calvarial defects with sulfated chitosan-coated calcium-deficient hydroxyapatite/ bone morphogenetic protein 2 scaffolds. Tissue Eng Part A. 2012 Jan;18(1-2):185-97. doi: 10.1089/ten.TEA.2011.0297

27. Yeo A, Wong WJ, Teoh S-H. Surface modification of PCLTCP scaffolds in rabbit calvaria defects: evaluation of scaffold degradation profile, biomechanical properties and bone healing patterns. J Biomed Mater Res A. 2010 Jul;93(4):1358-67. doi: 10.1002/jbm.a.32633

28. Goyenvalle E, Aguado E, Nguyen J-M, Passuti N, Le Guehennec L, Layrolle P, Daculsi G. Osteointegration of femoral stem prostheses with a bilayered calcium phosphate coating. Biomaterials. 2006 Mar;27(7):1119-28. doi: 10.1016/j.biomaterials.2005.07.039

29. Li J, Habibovic P, Yuan H, van den Doel M, Wilson CE, de Wijn JR, van Blitterswijk C a, de Groot K. Biological performance in goats of a porous titanium alloy-biphasic calcium phosphate composite. Biomaterials. 2007 Oct;28(29):4209-18. doi: 10.1016/j. biomaterials.2007.05.042

30. Ohgushi H, Okumura M, Tamai S, Shors EC, Caplan AI. Marrow cell induced osteogenesis in porous hydroxyapatite and tricalcium phosphate: a comparative histomorphometric study of ectopic bone formation. J Biomed Mater Res. 1990 Dec;24(12):1563-70. doi: 10.1002/jbm.820241202

31. Klein CP, Patka P, Wolke JG, de Blieck-Hogervorst JM, de Groot $\mathrm{K}$. Long-term in vivo study of plasma-sprayed coatings on titanium alloys of tetracalcium phosphate, hydroxyapatite and alphatricalcium phosphate. Biomaterials. 1994 Jan;15(2):146-50. doi: 10.1016/0142-9612(94)90264-X

32. Wheeler DL, Campbell AA, Graff GL, Miller GJ. Technical Note Histological and biomechanical evaluation of calcium phosphate coatings applied through surface-induced mineralization to porous titanium implants. J Biomed Mater Res. 1997 Mar;34(4):539-43. doi: 10.1002/(SICI)1097-4636

33. Lopez-Heredia M a, Sohier J, Gaillard C, Quillard S, Dorget M, Layrolle P. Rapid prototyped porous titanium coated with calcium phosphate as a scaffold for bone tissue engineering. Biomaterials. 2008 Jul;29(17):2608-15. doi: 10.1016/j.biomaterials.2008.02.021

34. Wang C, Karlis GA, Anderson GI, Dunstan CR, Carbone A, Berger G, Ploska U, Zreiqat H. Bone growth is enhanced by novel bioceramic coatings on Ti alloy implants. J Biomed Mater Res A. 2009 Aug;90(2):419-28. doi: 10.1002/jbm.a.32111

35. Borsari V, Fini M, Giavaresi G, Rimondini L, Consolo U, Chiusoli L, Salito A, Volpert A, Chiesa R, Giardino R. Osteointegration 
of titanium and hydroxyapatite rough surfaces in healthy and compromised cortical and trabecular bone: in vivo comparative study on young, aged, and estrogen-deficient sheep. J Orthoped Res. 2007 Sep;25(9):1250-60. doi: 10.1002/jor.20413

36. Walschot LHB, Aquarius R, Schreurs BW, Verdonschot N, Buma P. Osteoconduction of impacted porous titanium particles with a calcium-phosphate coating is comparable to osteoconduction of impacted allograft bone particles: in vivo study in a nonloaded goat model. J Biomed Mater Res B Appl Biomater. 2012 Aug;100(6):1483-9. doi: 10.1002/jbm.b.32716

37. Hirota M, Hayakawa T, Yoshinari M, Ametani A, Shima T, Monden Y, Ozawa T, Sato M, Koyama C, Tamai N, Iwai T, Tohnai I. Hydroxyapatite coating for titanium fibre mesh scaffold enhances osteoblast activity and bone tissue formation. Int J Oral Maxillofac Surg. 2012 Oct;41(10):1304-9. doi: 10.1016/j.ijom.2011.12.035

38. Karageorgiou V, Kaplan D. Porosity of 3D biomaterial scaffolds and osteogenesis. Biomaterials. 2005 Sep;26(27):5474-91. doi: 10.1016/j.biomaterials.2005.02.002

39. Wennerberg A, Albrektsson T. Effects of titanium surface topography on bone integration: a systematic review. Clin Oral Implants Res. 2009 Sep;20(Suppl 4):172-84. doi: 10.1111/j.16000501.2009.01775.x

40. Surmenev RA, Surmeneva MA, Ivanova AA. Significance of calcium phosphate coatings for the enhancement of new bone osteogenesis - A review. Acta Biomater. 2014 Mar;10(2):557-79. doi: 10.1016/j.actbio.2013.10.036

\section{Correspondence:}

Prof. Dr. Paulo Kharmandayan

Rua Tessália Vieira de Camargo, 126

Cidade Universitária "Zeferino Vaz"

Caixa Postal: 6111

13083-887 Campinas - SP Brasil

Tels.: (55 11)95020-2080 / (55 19)3521-7092

Fax: (55 19)3521-8043

pkharmand@hotmail.com

Received: Apr 24, 2014

Review: Jun 25, 2014

Accepted: July 23, 2014

Conflict of interest: none

Financial source: Biofabris National Institute of Science and Technology, Brazilian Ministry of Science and Technology (MCT)

${ }^{1}$ Research performed at Laboratory of Animal Quality Control, Multidisciplinary Center for Biological Investigation, Laboratory Animals Science and Division of Plastic Surgery, Department of Surgery, Faculty of Medical Sciences, University of Campinas (UNICAMP), Brazil. Part of $\mathrm{PhD}$ degree thesis, Postgraduate Program in Surgical Sciences. Tutor: Paulo Kharmandayan. 